\section{ORIGINAL RESEARCH}

\author{
A.K. Wakhloo \\ I. Linfante \\ C.F. Silva
}

E.A. Samaniego

G. Dabus

V. Etezadi

G. Spilberg

M.J. Gounis

\title{
Closed-Cell Stent for Coil Embolization of Intracranial Aneurysms: Clinical and Angiographic Results
}

\begin{abstract}
BACKGROUND AND PURPOSE: Recanalization is observed in $20-40 \%$ of endovascularly treated intracranial aneurysms. To further reduce the recanalization and expand endovascular treatment, we evaluated the safety and efficacy of closed-cell SACE.
\end{abstract}

MATERIALS AND METHODS: Between 2007 and 2010, 147 consecutive patients (110 women; mean age, 54 years) presenting at 2 centers with 161 wide-neck ruptured and unruptured aneurysms were treated by using SACE. Inclusion criteria were wide-neck aneurysms ( $>4 \mathrm{~mm}$ or a dome/neck ratio $\leq 2)$. Clinical outcomes were assessed by the mRS score at baseline, discharge, and follow-up. Aneurysm occlusion was assessed on angiograms by using the RS immediately after SACE and at follow-up.

RESULTS: Eighteen aneurysms (11\%) were treated following rupture. Procedure-related mortality and permanent neurologic deficits occurred in $2(1.4 \%)$ and 5 patients $(3.4 \%)$, respectively. In total, 7 patients (4.8\%) died, including 2 with reruptures. Of the 140 surviving patients, $113(80.7 \%)$ patients with 120 aneurysms were available for follow-up neurologic examination at a mean of 11.8 months. An increase in mRS score from admission to follow-up by 1, 2, or 3 points was seen in 7 (6.9\%), 1 (1\%), and $2(2 \%)$ patients, respectively. Follow-up angiography was performed in 120 aneurysms at a mean of 11.9 months. Recanalization occurred in 12 aneurysms (10\%), requiring retreatment in $7(5.8 \%)$. Moderate in-stent stenosis was seen in $1(0.8 \%)$, which remained asymptomatic.

CONCLUSIONS: This series adds to the evidence demonstrating the safety and effectiveness of SACE in the treatment of intracranial aneurysms. However, SACE of ruptured aneurysms and premature termination of antiplatelet treatment are associated with increased morbidity and mortality.

ABBREVIATIONS: ASA $=$ acetylsalicylic acid; ISAT $=$ International Subarachnoid Aneurysm Trial; $\mathrm{mRS}=$ modified Rankin Scale; RS = Raymond score; SACE = stent-assisted coil embolization

D espite ongoing concerns about the durability of endovascular treatment of intracranial aneurysms, coiling has been increasingly accepted worldwide. The multicenter randomized ISAT, ${ }^{1-3}$ showing long-term improved safety and clinical outcome in patients treated with coil embolization compared with open clipping, has accelerated this trend, ${ }^{4}$ increasing the number of patients being referred for endovascular treatment and thus further emphasizing the need to enhance the ability to treat intracranial aneurysms effectively. However, large, giant, and wide-neck aneurysms can be difficult to treat because of the significant risk of coil herniation from the aneurysm into the parent artery. ${ }^{5-7}$ While the goal of endovascular treatment is complete exclusion of the aneurysm from the circulation while preserving the parent and sidebranch artery lumen, this is often not possible. Even with adjunctive techniques such as balloon remodeling, large, giant, and wide-neck aneurysms remain challenging, with a signifi-

Received August 23, 2011; accepted after revision November 21

From the Department of Radiology (A.K.W., C.F.S., G.S., M.J.G.), New England Center for Stroke Research, University of Massachusetts Medical School, Worcester, Massachusetts; Baptist Cardiac and Vascular Institute (I.L., E.A.S., G.D.), Miami Florida; and Department of Radiology (V.E.), University of Pennsylvania, Philadelphia, Pennsylvania.

Please address correspondence to Ajay K. Wakhloo, MD, PhD, Division Neuroimaging and Intervention, 55 Lake Ave N, S2-840, Worcester, MA 01655; e-mail: Ajay.Wakhloo@ umassmed.edu

Indicates open access to non-subscribers at www.ajnr.org

http://dx.doi.org/10.3174/ajnr.A3034

cant number of subtotal occlusions. In addition, aneurysm recanalization is observed in $20 \%-40 \%$ of cases due to coil compaction, migration of coils into the aneurysm thrombus, or aneurysm growth..$^{7-10}$

Introduction of stents designed as an adjunct tool for coiling has been shown, in the short-term, to be of beneficial value. ${ }^{11-15}$ However, a variety of devices, different in their design and coating, was used with a high periprocedural mortality and morbidity. ${ }^{15,16}$ This study was designed to evaluate 1 specific stent available for aneurysm treatment, regarding the periprocedural and safety profile as well as efficacy. Our hypothesis was that stent-assisted coil embolization reduces recanalization and retreatment rates compared with historical controls ${ }^{17}$ without impacting procedural safety in a subgroup of wide-neck aneurysms or in those with a dome/neck ratio of $<2$.

\section{Materials and Methods}

\section{Patients and Techniques}

From June 2007 to June 2010, consecutive patients harboring intracranial aneurysms treated with Enterprise (Codman Neurovascular, Raynham, Massachusetts) SACE were enrolled in a prospective data base at 2 participating centers. All procedures were approved by the local institutional review board at each participating site. Inclusion criteria were the following: 1) wide-neck aneurysm: defined as one having a neck dimension that is $>4 \mathrm{~mm}$ or a dome/neck ratio that is $\leq 2 ; 2$ ) parent vessel diameter of $\leq 4 \mathrm{~mm} ; 3$ ) any use of a closed-cell 
stent for coil embolization; and 4) patient or health care proxy informed consent. Patients younger than 18 years and pregnant women were excluded. Patients treated with open-cell stents were excluded. At the participating centers, all ruptured aneurysms are treated, and treatment of unruptured aneurysms is performed after careful assessment of perceived risk factors for rupture ${ }^{18,19}$ and consultation with our multidisciplinary cerebrovascular team and patients.

\section{Angiographic and Endovascular Procedures}

All endovascular procedures were performed by senior neurointerventionalists by using a biplane angiography unit with 3D rotational angiography capability (Allura Xper FD20/20; Philips Healthcare, Best, the Netherlands) with patients under general anesthesia. $\mathrm{Pa}-$ tients were given ASA ( $80 \mathrm{mg}$ ) and clopidogrel $(75 \mathrm{mg})$ for a minimum of 3 days before the procedure. Dual antiplatelet treatment was continued for a minimum of 6 months, followed by life-long continuation of ASA. In cases of acute aneurysm rupture, patients were administered $350 \mathrm{mg}$ of ASA and $150 \mathrm{mg}$ of clopidogrel through a nasogastric tube at a minimum of 1 hour before commencing the procedure. Most important, in ruptured cases, the neurosurgery and neurointensive care teams were consulted to assess the need for ventriculostomy before administering antiplatelet medication. Endovascular access was obtained by a standard transfemoral approach. Following access, patients were heparinized to maintain activated clotting time $>250$ seconds (for ruptured and unruptured aneurysms). The stent delivery microcatheter was first positioned across the neck of the aneurysm followed by placement of the coiling microcatheter within the aneurysm. All aneurysms were embolized by using the semi-jailing ${ }^{20}$ or jailing technique. Aneurysms were coiled as densely as possible with coils selected per the operator's preference. Any technical complication, with or without clinical sequelae, was recorded.

Aneurysm occlusion was estimated by independent reviewers not involved in patient care, by using a 3-point $\mathrm{RS}^{21}$ (RS 1, complete obliteration of aneurysm and neck; RS 2, neck remnant without contrast filling the aneurysm sac; and RS 3, contrast filling the aneurysm sac) immediately after SACE and at follow-up. After the procedure, patients were transferred to the neurosurgical intensive care unit. Packing attenuation, the volume ratio of implanted coils to the volume of the aneurysm, was calculated as previously described. ${ }^{9} \mathrm{We}$ calculated coil volume for each aneurysm, assuming that the coil was a solid cylinder by using the primary coil diameter given in the manufacturer's specifications.

\section{Clinical Evaluation}

A complete neurologic examination was performed in all patients at baseline, immediately after the procedure, at discharge, and at follow-up by experienced physicians certified in stroke assessment. An $\mathrm{mRS}$ score was assessed at baseline for unruptured cases, at discharge, and at follow-up evaluations. For ruptured aneurysms, the Hunt and Hess grade was recorded at baseline. Primary adverse events included death and stroke. Secondary adverse events recorded were transient ischemic attack, the need for re-intervention, and the presence of hematomas. Residual aneurysm size was determined by angiography. Medical histories, procedural reports, and clinical outcomes were recorded in this prospective data base.

\section{Statistical Analysis}

All data are presented as the mean \pm the standard error of the mean. Comparisons of categoric data were performed by using the Fisher

\begin{tabular}{lc}
\hline \multicolumn{2}{l}{ Table 1: Patient demographics and aneurysm information } \\
\hline \multicolumn{2}{l}{ No. } \\
\hline Patients & 147 \\
Aneurysms & 161 \\
Females & $110(74.8 \%)$ \\
Mean age (yr) & 54.0 \\
Age range (yr) & $27-81$ \\
Presentation/indications for treatment & \\
SAH & $18(11 \%)$ \\
Headache/incidental & $80(55 \%)$ \\
Recurrence after coiling & $27(18 \%)$ \\
Stroke/transient ischemic attack & $13(9 \%)$ \\
Mass effect & $7(5 \%)$ \\
Recurrence after clipping/failed clipping & $2(1 \%)$ \\
Aneurysm dimensions & \\
Mean aneurysm dome size (SEM) & $6.5(0.4) \mathrm{mm}$ \\
Mean aneurysm neck size (SEM) & $5.1(0.3) \mathrm{mm}$ \\
Dome/neck ratio (SEM) & $1.3(0.04)$ \\
Aneurysm Location & \\
ACA & $4(2.5 \%)$ \\
AcomA & $15(9.5 \%)$ \\
BA & $15(9.5 \%)$ \\
Cavernous ICA & $14(9 \%)$ \\
Paraclinoid ICA & $18(11 \%)$ \\
Extracranial ICA & $3(2 \%)$ \\
ICA terminus & $6(4 \%)$ \\
MCA & $18(11 \%)$ \\
Ophthalmic/paraophthalmic & $23(14 \%)$ \\
PcomA & $23(14 \%)$ \\
PICA & $2(1 \%)$ \\
SCA & $2(1 \%)$ \\
Superior hypophyseal & $12(7.5 \%)$ \\
VA & $6(4 \%)$ \\
Morphology & \\
Wide-neck saccular & $95(60 \%)$ \\
Fusiform/dissecting & $24(15 \%)$ \\
Blister & $8(5 \%)$ \\
Recurrence (clipping or coiling) & $34(20 \%)$ \\
\hline Not-stM & \\
\hline
\end{tabular}

Note:-SEM indicates standard error of the mean; ACA, anterior cerebral artery; AcomA, anterior communicating artery; BA, basilar tip; PcomA, posterior communicating artery: SCA, superior cerebellar artery; VA vertebral artery.

exact test in GraphPad InStat (http://www.softpedia.com/get/Others/ Finances-Business/GraphPad-InStat.shtml). Significant differences were established for $P<.05$.

\section{Results}

\section{Patient Information and Technical Results}

We enrolled 147 patients harboring 161 aneurysms that were embolized via SACE. Eighteen aneurysms (11\%) were treated acutely following rupture. Patient demographic information and aneurysm characteristics/location are provided in Table 1. Most aneurysms were discovered incidentally (55\%) and were of wide-neck saccular morphology $(60 \%)$. The mean aneurysm and neck diameters were $6.5 \pm 0.4$ and $5.1 \pm 0.3 \mathrm{~mm}$, respectively; the dome/neck ratio was $1.3 \pm 0.04$. In 2 cases of a small aneurysm and a dissecting aneurysm, no coils were used in conjunction with the stent. In another 2 cases, the stent was resheathed following successful coil embolization by using the semi-jailing technique. ${ }^{20}$ In total, 167 stents were used (1.03 stents/aneurysm, 6 patients received 2 stents). The packing attenuation obtained was $43 \pm 3 \%$. Of all stented vessels, 19 measured $<2 \mathrm{~mm}$ (mean, $1.7 \pm 0.04 \mathrm{~mm}$ ).

During the procedure, clot formation on the surface of the 


\begin{tabular}{|c|c|c|}
\hline $\begin{array}{l}\text { Change in } \\
\text { mRS }^{a}\end{array}$ & $\begin{array}{c}\text { Frequency (No. } \\
\text { of Patients) }\end{array}$ & Description (No.) \\
\hline 1 & 7 & $\begin{array}{l}\text { New or more severe headache (4), mild } \\
\text { extremity weakness (3), visual field } \\
\text { deficit (1) }\end{array}$ \\
\hline 2 & 1 & $\begin{array}{l}\text { Stroke after termination of antiplatelet } \\
\text { therapy } 60 \text { days posttreatment }\end{array}$ \\
\hline 3 & 2 & $\begin{array}{l}\text { Anterior choroidal artery stroke }(1) \text {; } \\
\text { stroke after termination of } \\
\text { antiplatelet therapy } 10 \text { months post- } \\
\text { treatment (1) }\end{array}$ \\
\hline $6^{b}$ & 2 & $\begin{array}{l}\text { Sneddon syndrome, withdrawal of } \\
\text { medical care after thromboembolism } \\
\text { (1); stroke } 6 \text { months after treatment } \\
\text { (1) }\end{array}$ \\
\hline
\end{tabular}

a Increase in mRS from baseline $\left(\mathrm{mRS}_{\text {follow-up }}-\mathrm{mRS}_{\text {baseline }}\right)$.

${ }^{b}$ All patients with unruptured aneurysms who died, absolute mRS score.

\begin{tabular}{|c|c|c|}
\hline $\mathrm{mRS}$ & $\begin{array}{l}\text { Frequency (No. } \\
\text { of Patients) }\end{array}$ & Description (No.) \\
\hline 0 & 8 & \\
\hline 2 & 3 & $\begin{array}{l}\text { Residual deficit after SAH (2), stroke due to } \\
\text { stent occlusion after stopping antiplatelet } \\
\text { therapy for shunt placement } 2 \text { months after } \\
\text { procedure (1) }\end{array}$ \\
\hline 3 & 1 & $\begin{array}{l}\text { Symptomatic intracranial hemorrhage following } \\
\text { shunt revision while on antiplatelet therapy } \\
\text { (1) }\end{array}$ \\
\hline 6 & 5 & $\begin{array}{l}\text { Aneurysm rebleeding (2), complications of SAH/ } \\
\text { vasospasm (3) }\end{array}$ \\
\hline
\end{tabular}

ane patient lost to follow-up.

stent was observed in $11(6.8 \%)$ cases, all of which were successfully treated with intra-arterial administration of abciximab (5-18 mg). ${ }^{22}$ During coiling, inadvertent aneurysm perforation was encountered in 3 aneurysms (1.9\%) without clinical sequelae. Angiography revealed vasospasm due to catheter manipulation in $20(12.4 \%)$ cases, which promptly resolved with local intra-arterial administration of nicardipine (2-15 mg). ${ }^{23}$ A single (0.6\%) instance of proximal stent migration occurred following SACE of a basilar tip aneurysm, in which a 14-mm stent was deployed from the right P1 segment of the posterior cerebral artery to the basilar artery without untoward events. In $6(3.7 \%)$ cases, coil material herniated into the parent vessel that was subsequently pinned between the stent and artery following full stent deployment.

\section{Clinical Outcome}

Seven patients $(4.8 \%)$ died, including 2 with reruptures $(\mathrm{Ta}-$ bles 2 and 3 ). There were $5(3.4 \%)$ and $3(2 \%)$ minor and major strokes, respectively, within 30 days of the procedure. During this period, 6 patients $(4.1 \%)$ experienced a transient ischemic attack. The 30-day combined cardiac and pulmonary complication rate was $2.5 \%$. Five patients $(3.4 \%)$ had accesssite complications, including groin hematoma (4 patients) and suture-induced femoral artery constriction requiring surgical repair (1 patient). One patient developed hydrocephalous 30 days after SACE of a ruptured aneurysm.

Of the 140 surviving patients, 113 (80.7\%) with 120 aneu-

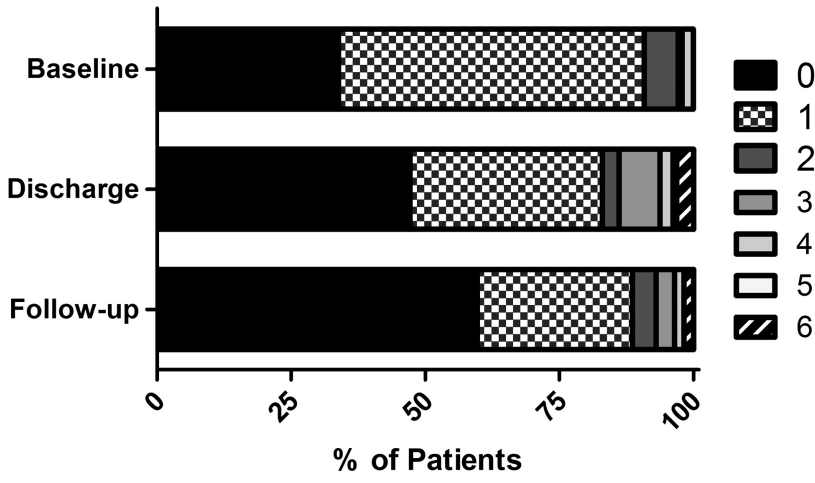

Fig 1. $m R S$ score as a percentage of patients scored at baseline (141 patients, excludes those presenting with aneurysmal subarachnoid hemorrhage), discharge (159 patients), and follow-up (113 patients). Two patients having 2 aneurysms each were treated in a single session.

rysms were available for follow-up neurologic examination at a mean of 11.8 months (95\% CI, 10.5-13.2 months). Of patients in the unruptured aneurysm cohort available for follow-up $(n=101)$, an increase in the mRS score from admission to follow-up by 1,2 , or 3 points was seen in 7 (6.9\%), 1 (1\%), and $2(2 \%)$ patients, respectively (Fig 1). After adjudication of complications by the senior neurointerventionalists, procedure-related mortality and permanent neurologic deficits occurred in $2(1.4 \%)$ and 5 patients $(3.4 \%)$, respectively (Tables 2 and 3 ).

\section{Angiographic Results}

Follow-up angiography was performed in 120 aneurysms at a mean of 11.9 months (95\% CI, 10.6-13.2 months) (illustrative case, Fig 2). Of the angiographic follow-ups, the number of aneurysms at each time point was the following: 3 at $<6$ months, 48 from 6 to 11 months, 62 from 12 to 24 months, and 7 at $>24$ months. Aneurysms were more likely to be completely occluded at follow-up, suggesting progressive thrombosis $(P<.0001)$ (Fig 3). Recanalization, defined as any increase in the RS from the postprocedural angiogram, was seen in 12 aneurysms (10\%). Of the recanalized aneurysms, 7 $(5.8 \%)$ were subsequently retreated. No adverse events were seen as a result of the retreatment. Intimal hyperplasia producing a mild $(<20 \%)$ or moderate $(>20 \% ;<70 \%)$ narrowing was seen in $6(5 \%)$ and $1(0.8 \%)$ of the stented segments, respectively. All patients with angiographic evidence of vessel narrowing remained asymptomatic. Of the stented segments in vessels that measured $<2 \mathrm{~mm}$, there were $2(10.5 \%)$ mild and $1(5.3 \%)$ moderate case of in-stent stenosis.

\section{Discussion}

Technologies such as balloon remodeling ${ }^{24,25}$ and stent-assisted coiling ${ }^{11-13,26,27}$ have enabled endovascular treatment of wideneck complex aneurysms. A large multicenter prospective trial recently compared the safety profile of the balloon remodeling technique with that of coil embolization alone in unruptured aneurysms. ${ }^{28}$ The morbidity and mortality in the balloon remodeling group were $2.3 \%$ and $1.4 \%$, respectively, and rates did not differ from those in the standard treatment group. A recent retrospective study of SACE in both ruptured and unruptured aneurysms reported procedure-related morbidity and mortality rates of $7.4 \%$ and $4.6 \%$, respectively. ${ }^{15}$ This latter study included 

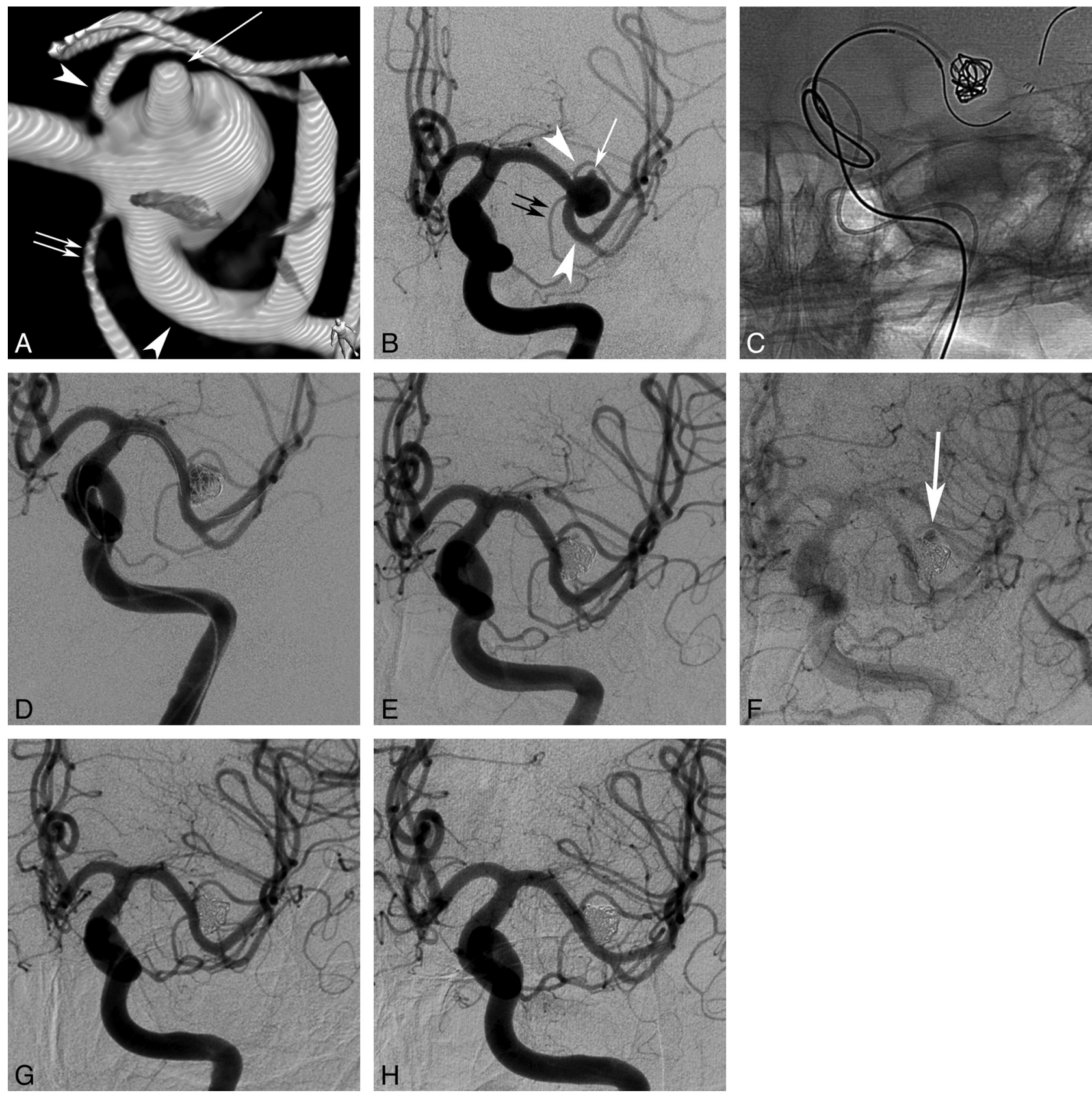

Fig 2. A 59-year-old man referred for embolization of an incidentally discovered MCA aneurysm. 3D rotational angiography $(A$, frontal view) and DSA $(B)$ show a wide-neck aneurysm involving both the smaller superior and the larger inferior M2 divisions (arrowheads) as well as the anterior temporal artery (double arrows). Note an aneurysm bleb projecting superiorly (arrow). Partial stent deployment (semi-jailing technique ${ }^{20}$ ) with placement of a framing coil $(C)$. Compartmental coiling with smaller fill coils and deployment of the stent $(D)$. Final early and late arterial phase angiogram ( $E$ and $F$ ) shows obliteration of the aneurysm with delayed filling of the bleb (arrow, Raymond Class 3 ) and preservation of all involved MCA branches. Twenty-four-hour follow-up angiogram before discharge after discontinuation of the intraprocedural therapeutic heparin shows lack of delayed contrast filling of the bleb, most likely representing further thrombosis $(G)$. Twelve-month follow-up angiogram $(H)$ shows stable and complete aneurysm occlusion with preservation of all MCA branches.

all commercially available stent technologies, and the authors reported that procedure-related complications were dependent on the stent used. To remove this variable, a multicenter registry was performed to evaluate the acute clinical outcomes by using the Enterprise stent, and it found permanent morbidity and mortality rates of $2.8 \%$ and $2 \%$, respectively. ${ }^{14}$

We report the midterm clinical outcome for aneurysms treated by closed-cell SACE. In unruptured aneurysms, overall morbidity, defined as any increase in mRS at follow-up, and mortality were $10.3 \%$ and $1.6 \%$, respectively. Permanent major morbidity (mRS score of $\geq 2$ at follow-up) in the unrup- tured aneurysm cohort was seen in 4 patients (3.1\%). If one uses similar criteria for comparison of SACE in this series with balloon-remodeling previously reported ${ }^{28}$ mortality is similar and morbidity is slightly higher. Although it is convenient to compare these data with the balloon-remodeling experience, our centers frequently use the balloon-remodeling technique, and SACE is reserved for aneurysms with an exceedingly poor dome/neck ratio that approaches 1. Additionally, in this series, poor outcomes were mostly related to thromboembolic complications associated with premature termination of systemic dual-antiplatelet therapy rather than the SACE procedure. 


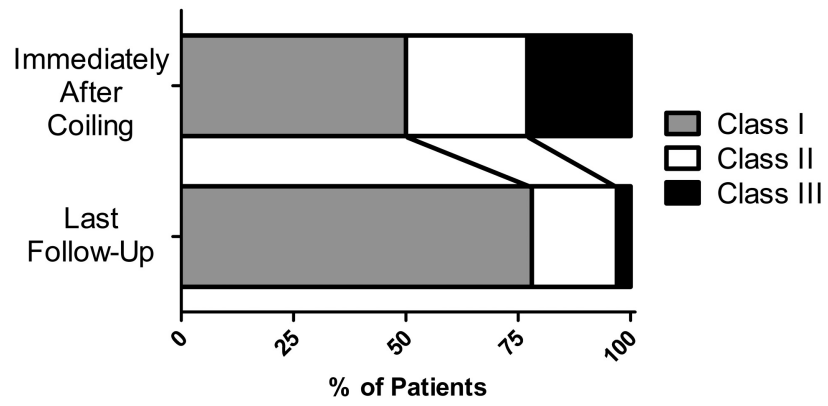

Fig 3. RS as a percentage of patients scored immediately after the procedure (161 aneurysms) and at latest follow-up (120 aneurysms). All aneurysms were assessed from DSA studies performed in the view best demonstrating the aneurysm neck.

We enrolled 18 patients in the acute period following subarachnoid hemorrhage, and the morbidity and mortality rates were $22 \%$ and $28 \%$, respectively. These outcomes are similar to those reported for SACE in ruptured aneurysms. ${ }^{16}$ However, this complication rate does not compare favorably with that in the ISAT, in which $23.7 \%$ of patients were dependent or dead 1 year following endovascular coiling. ${ }^{1}$ One explanation for the lower rate of good outcomes in our study might be the inclusion of dissecting aneurysms $(n=6,33 \%)$, which were excluded in the ISAT trial. Two significant complications occurred in our study when patients developed hydrocephalous 1-2 months following SACE of ruptured aneurysms. In 1 case, antiplatelet therapy was halted for shunt placement with subsequent in-stent thrombosis. In another case, shunt revision was performed with the patient on antiplatelet therapy, leading to symptomatic intracranial hemorrhage. Additionally, 2 deaths were associated with aneurysm rebleeding after SACE. One case of rebleeding was from a dissecting aneurysm, where the rebleed occurred 4 days after embolization. These data demonstrate the increased risk of using stents for aneurysm embolization versus coiling alone or balloon-remodeling in ruptured aneurysms.

Recently, a large meta-analysis reported aneurysm recurrence and retreatment following coil embolization in $20.8 \%$ and $10.3 \%$ of cases, respectively. ${ }^{17}$ Angiographic results reported herein demonstrate a high rate of progressive thrombosis of the aneurysm and complete aneurysm obliteration on follow-up. Aneurysm recurrence (10\%) and retreatment (5.8\%) were considerably lower with SACE despite the wideneck morphology, which is associated with worse angiographic outcomes. ${ }^{10}$ Intimal hyperplasia induced by the presence of the stent within the parent artery leads to remodeling, thereby permanently excluding the aneurysm.

Limitations of this study are the lack of a direct control group and the relatively small number of ruptured aneurysms included in the study. Follow-up at a mean of 11.8 months was available in only $80 \%$ of patients. Patients were lost to follow-up either due to refusal to return for clinical examination or angiography or change of contact information with no forwarding instructions. Because our study enrolled prospectively all consecutive patients receiving SACE with a closedcell device, our study included heterogeneous aneurysm morphologies including blister and dissecting aneurysms as well as both ruptured and unruptured aneurysms. We further included 2 cases in which the device was resheathed and not implanted, as well as 2 cases in which coiling was not possible.

\section{Conclusions}

SACE of wide-neck unruptured aneurysms with a closed-cell device is safe and produces durable and high occlusion rates; however, increased morbidity and mortality observed in ruptured aneurysms are associated with dual-antiplatelet treatment required for stent placement.

Disclosures: Ajay Wakhloo—UNRELATED: Board Membership: Surpass Medical Ltd, Comments: unpaid, Consultancy. Codman Johnson \& Johnson, ${ }^{*}$ Stryker Neurovascular, ${ }^{*}$ Surpass Medical Ltd, Employment. Surpass Medical Ltd, Grants/Grants Pending: National Institutes of Health, Philips Med; Payment for Lectures (including service on speakers bureaus): Codman Johnson \& Johnson, Harvard Medical School, Live International Neurovascular Conference, Patents (planned, pending, or issued): head rest, Stock/Stock Options: Surpass Medical Ltd, Travel/Accommodations/Meeting Expenses Unrelated to Activities Listed: Codman Johnson \& Johnson. Italo Linfante-UNRELATED: Board Membership: Codman Neurovascular, Comments: became Advisory Board member for Codman Neurovascular well after the analysis of the data presented in study, Consultancy. Codman Neurovascular, Payment for Lectures (including service on Speakers Bureaus). Codman Neurovascular, Concentric Medical, Payment for Development of Educational Presentations: Codman Neurovascular. Guilherme Dabus-RELATED: Consulting Fee or Honorarium: Codman Neurovascular, UNRELATED: Stock/Stock Options: Surpass Medical. Ltd, Com ments: shareholder. Matthew Gounis_UNRELATED: Consultancy. Codman Neurovascular, Micrus Endovascular, Comments: fee-for-service consultation, Grants/Grants Pending: National Institutes of Health, ${ }^{*}$ Codman Neurovascular, ${ }^{*}$ Stryker Neurovascular, ${ }^{*}$ ev3, ${ }^{*}$ Concentric Medical, ${ }^{*}$ Neurointerventional Therapeutics, ${ }^{*}$ Thrombolysis Science, ${ }^{*}$ Sanofi-Aventis, ${ }^{*}$ Neuravi, ${ }^{*}$ Philips Healthcare, ${ }^{*}$ Soteira, ${ }^{*}$ Money paid to the institution.

\section{References}

1. Molyneux A, Kerr R, Stratton I, et al, for the International Subarachnoid Aneurysm Trial (ISAT) Collaborative Group. International subarachnoid aneurysm trial (ISAT) of neurosurgical clipping versus endovascular coiling in 2143 patients with ruptured intracranial aneurysms: a randomised trial. Lancet 2002;360:1267-74

2. Molyneux AJ, Kerr RS, Yu LM, et al. International subarachnoid aneurysm trial (ISAT) of neurosurgical clipping versus endovascular coiling in 2143 patients with ruptured intracranial aneurysms: a randomised comparison of effects on survival, dependency, seizures, rebleeding, subgroups, and aneurysm occlusion. Lancet 2005;366:809-17

3. Molyneux AJ, Kerr RS, Birks J, et al. Risk of recurrent subarachnoid haemorrhage, death, or dependence and standardised mortality ratios after clipping or coiling of an intracranial aneurysm in the International Subarachnoid Aneurysm Trial (ISAT): long-term follow-up. Lancet Neurol 2009;8:427-33

4. Alshekhlee A, Mehta S, Edgell RC, et al. Hospital mortality and complications of electively clipped or coiled unruptured intracranial aneurysm. Stroke 2010;41:1471-76

5. Lavine SD, Larsen DW, Giannotta SL, et al. Parent vessel Guglielmi detachable coil herniation during wide-necked aneurysm embolization: treatment with intracranial stent placement-two technical case reports. Neurosurgery 2000;46:1013-17

6. Phatouros CC, Sasaki TY, Higashida RT, et al. Stent-supported coil embolization: the treatment of fusiform and wide-neck aneurysms and pseudoaneurysms. Neurosurgery 2000;47:107-13

7. Gallas S, Pasco A, Cottier J, et al. A multicenter study of 705 ruptured intracranial aneurysms treated with Guglielmi detachable coils. AJNR Am J Neuroradiol 2005;26:1723-31

8. Sluzewski M, van Rooij WJ, Slob MJ, et al. Relation between aneurysm volume, packing, and compaction in 145 cerebral aneurysms treated with coils. Radiology 2004;231:653-58

9. Wakhloo AK, Gounis MJ, Sandhu JS, et al. Complex-shaped platinum coils for brain aneurysms: higher packing density, improved biomechanical stability, and midterm angiographic outcome. AJNR Am J Neuroradiol 2007;28:1395400

10. Murayama Y, Nien YL, Duckwiler G, et al. Guglielmi detachable coil embolization of cerebral aneurysms: 11 years' experience. J Neurosurg 2003;98: 959-66

11. Akpek S, Arat A, Morsi H, et al. Self-expandable stent-assisted coiling of widenecked intracranial aneurysms: a single-center experience. AJNR Am J Neuroradiol 2005;26:1223-31

12. Biondi A, Janardhan V, Katz JM, et al. Neuroform stent-assisted coil embolization of wide-neck intracranial aneurysms: strategies in stent deployment and midterm follow-up. Neurosurgery 2007;61:460-68

13. Fiorella D, Albuquerque FC, Deshmukh VR, et al. Usefulness of the Neuroform stent for the treatment of cerebral aneurysms: results at initial (3-6-mo) follow-up. Neurosurgery 2005;56:1191-201

14. Mocco J, Snyder KV, Albuquerque FC, et al. Treatment of intracranial aneu- 
rysms with the Enterprise stent: a multicenter registry. J Neurosurg 2009;110: 35-39

15. Piotin M, Blanc R, Spelle L, et al. Stent-assisted coiling of intracranial aneurysms: clinical and angiographic results in 216 consecutive aneurysms. Stroke 2010;41:110-15

16. Tähtinen OI, Vanninen RL, Manninen HI, et al. Wide-necked intracranial aneurysms: treatment with stent-assisted coil embolization during acute (72 hours) subarachnoid hemorrhage-experience in 61 consecutive patients. Radiology 2009;253:199-208

17. Ferns SP, Sprengers ME, van Rooij WJ, et al. Coiling of intracranial aneurysms: a systematic review on initial occlusion and reopening and retreatment rates. Stroke 2009;40:e523-529

18. Wiebers DO, Whisnant JP, Huston J 3rd, et al, for the International Study of Unruptured Intracranial Aneurysms Investigators. Unruptured intracranial aneurysms: natural history, clinical outcome, and risks of surgical and endovascular treatment. Lancet 2003;362:103-10

19. Chmayssani M, Rebeiz JG, Rebeiz TJ, et al. Relationship of growth to aneurysm rupture in asymptomatic aneurysms $\leq 7 \mathrm{~mm}$ : a systematic analysis of the literature. Neurosurgery 2011;68:1164-71, discussion 1171.

20. Hong B, Patel NV, Gounis MJ, et al. Semi-jailing technique for coil embolization of complex, wide-necked intracranial aneurysms. Neurosurgery 2009;65:1131-38
21. Roy D, Milot G, Raymond J. Endovascular treatment of unruptured aneurysms. Stroke 2001;32:1998-2004

22. Gralla J, Rennie ATM, Corkill RA, et al. Abciximab for thrombolysis during intracranial aneurysm coiling. Neuroradiology 2008;50:1041-47

23. Linfante I, Delgado-Mederos R, Andreone V, et al. Angiographic and hemodynamic effect of high concentration of intra-arterial nicardipine in cerebral vasospasm. Neurosurgery 2008;68:1080-86

24. Mericle RA, Wakhloo AK, Rodriguez R, et al. Temporary balloon protection as an adjunct to endosaccular coiling of wide-necked cerebral aneurysms: technical note. Neurosurgery 1997;41:975-78

25. Moret J, Cognard C, Weill A, et al. Reconstruction technic in the treatment of wide-neck intracranial aneurysms: long-term angiographic and clinical results-apropos of 56 cases. J Neuroradiol 1997;24:30-44

26. Wakhloo AK, Lanzino G, Lieber BB, et al. Stents for intracranial aneurysms: the beginning of a new endovascular era? Neurosurgery 1998;43:377-79

27. Wakhoo AK, Mandell J, Gounis MJ, et al. Stent-assisted reconstructive endovascular repair of cranial fusiform atherosclerotic and dissecting aneurysms: long-term clinical and angiographic follow-up. Stroke 2008;39:3288-96

28. Pierot L, Spelle L, Leclerc X, et al. Endovascular treatment of unruptured intracranial aneurysms: comparison of safety of remodeling technique and standard treatment with coils. Radiology 2009;251:846-55 